\title{
IMPLANTAÇÃO DO CONTROLE AUTOMÁTICO DE GAP DE TRABALHO NO ROLLER PRESS PARA MAXIMIZAÇÃO DA QUALIDADE DO PELLET FEED*
}

\author{
Renato Luciano de Araújo Menezes ${ }^{1}$ \\ Paulo Henrique Cardoso Mendes ${ }^{2}$ \\ Gustavo Ferreira Viana ${ }^{3}$ \\ Marcos Vinicius da Silva Cavalcante \\ Marcelo de Castro Souza \\ José Geraldo Pereira ${ }^{6}$
}

\section{Resumo}

O objetivo do presente trabalho é evidenciar os resultados do incremento de superfície específica obtidos pelo roller press da Usina 3 da Samarco Mineração S.A.. A metodologia utilizada baseou-se em informações de projeto do equipamento e análises estatísticas aplicadas ao processo de prensagem bem como 0 desenvolvimento de um indicador de eficiência imune às variações de qualidade do minério. Basicamente esse trabalho buscou otimizar as variáveis de processo capazes de gerar melhores resultados de incremento na superfície específica do minério. (Como resultado do trabalho foi verificado um aumento considerável nos resultados de eficiência no incremento de superfície específica).

Palavras-chave: Prensa; Específica; Superfície; HPGR.

\section{OPTIMIZATION OF THE ROLLER PRESS ON PROCESSING LINE OF PELLET FEED: GAP CONTROL TO OPTIMIZE THE PELLET FEED QUALITY}

\section{Abstract}

The purpose of this paper is to show how to optimize the quality results of the pellet feed processed in the plant 3 HPGR at Samarco Mineração S.A. The employed methodology have utilized information from the equipment's project and statistical analysis of the pellet feed pressing process to develop an efficiency index without dependency with the quality variations of the processed ore. Basically this paper sought optimizes the process variables that are able to generate the best results of increase in the specific surface of the ore. As results this paper had verified considerable increase in the efficiency of increase in the pellet feed's specific surface.

Keywords: Roller; Press; Grinding; HPGR.

1 Engenharia Metalúrgica, Engenheiro, Engenheiro de Processo, Gerência de Produção, Samarco Mineração SA, Anchieta, Espírito Santo, Brasil.

2 Engenharia de Controle e Automação, Engenheiro, Engenheiro de Automação, Gerência de Engenharia de Processos e Automação, Samarco Mineração SA, Anchieta, Espírito Santo, Brasil.

3 Engenharia Elétrica, Engenheiro, Engenheiro de Automação, Gerência de Processos e Automação, Samarco Mineração SA, Anchieta, Espírito Santo, Brasil.

4 Engenharia de Controle e Automação, Engenheiro, Engenheiro de Processo, Gerência de Produção, Samarco Mineração SA, Anchieta, Espírito Santo, Brasil.

5 Técnico de Automação, Técnico, Técnico de Automação, Gerência de Engenharia de Processos e Automação, Samarco Mineração SA, Anchieta, Espírito Santo, Brasil.

6 Engenharia Metalúrgica, M. Sc., Engenheiro de Processo, Gerência de Produção, Samarco Mineração SA, Anchieta, Espírito Santo, Brasil. 


\section{INTRODUÇÃO}

Atualmente a Samarco Mineração possui 4 roller press (Figura 1) que foram instaladas a partir de 2003 e que ficam localizadas entre os processos de filtragem e pelotamento com o objetivo de permitir que ambos os processos citados obtenham os melhores resultados possíveis. As prensas de rolos atuais possuem capacidade variável de acordo com a usina em que operam [1].

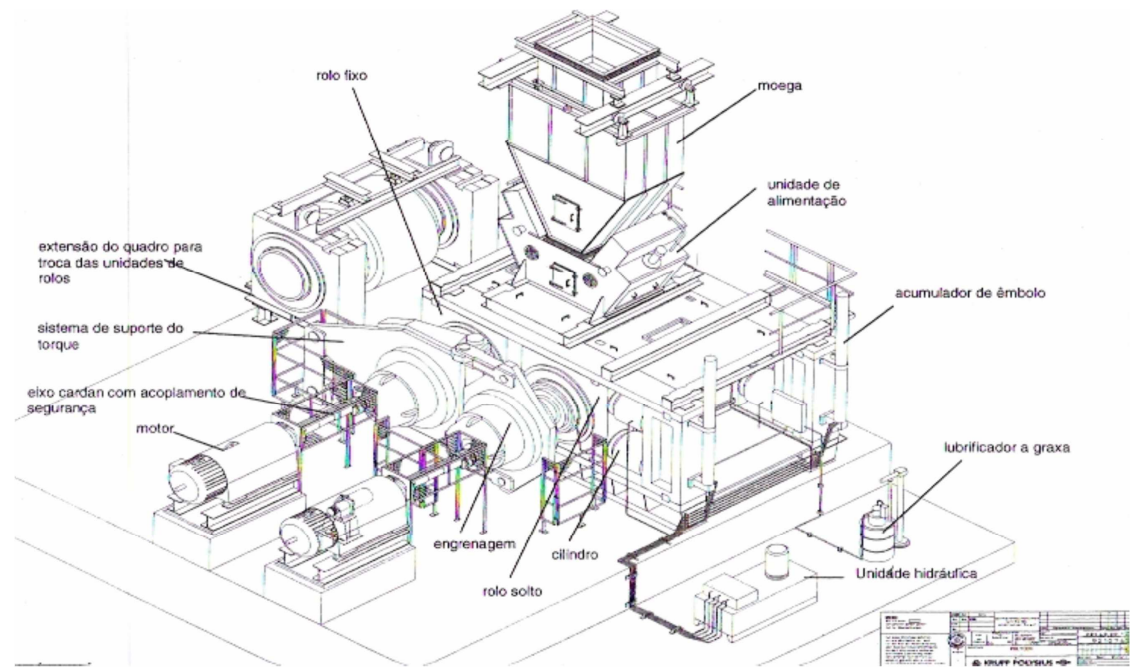

Figura 1. Desenho esquemático do Roller Press.

A variável de controle principal na cominuição do pellet feed via roller press é a Superfície Específica ou Blaine, que é um indicador paradoxal em relação aos processos de filtragem e de pelotamento, pois enquanto uma superfície específica mais baixa induz a melhores resultados na filtragem, aumentando a permeabilidade da torta, o pelotamento necessita de superfícies específicas do pellet feed mais altas para operar com bom desempenho e melhor acabamento da pelota crua, o que favorece a qualidade do produto final [1].

Sendo assim faz-se necessário o processo de prensagem do material para permitir que $\mathrm{o}$ pellet feed produzido pela concentração seja mais adequado à filtragem $\mathrm{e}$ para que a pelotização do minério ocorra da melhor maneira possível [1].

De posse dessas informações pode-se afirmar que os roller press podem impedir um melhor desempenho da produção em alguns momentos, sendo necessário um melhor desenvolvimento e controle do processo.

Esse trabalho foi desenvolvido no roller press da usina 3, que a princípio possuía a pressão aplicada nos rolos como a principal referência de controle.

O trabalho teve como objetivo melhorar os resultados de qualidade obtidos pelo roller press da usina 3 através do controle do gap, já que muitas vezes a pressão aplicada era alta, mas com o equipamento trabalhando totalmente fechado grande parte da energia era transferida para a própria estrutura, gerando resultados insatisfatórios [2,3].

\section{MATERIAIS E MÉTODOS}

A metodologia utilizada no trabalho partiu primeiramente do levantamento de informações teóricas em relatórios e manuais fornecidos pelo fabricante do equipamento bem como análises estatísticas para desenvolvimento de um indicador de eficiência do processo e verificação dos resultados obtidos. 
Primeiramente foram levantados quais os principais parâmetros a serem controlados na operação da roller press, são eles:

O Gap Zero, que é a mínima distância entre o rolo fixo e o móvel, é ajustado usando os 4 espaçadores que estão montados nos dois lados da roller press. Foi verificado que um ajuste de $10 \mathrm{~mm}$ é suficiente para garantir a produtividade do equipamento na faixa de umidade do pellet feed praticada atualmente pela Samarco Mineração [2].

A pressão de trabalho, que define a força específica de moagem, que na prática é o parâmetro que indica a tendência de cominuição do minério [2].

A pressão de trabalho é dependente da produtividade do equipamento, da umidade do pellet feed processado e da velocidade dos rolos (Figura 2) além do gap zero.

Matriz de Dispersão de Pressão em Função das Outras Variáveis

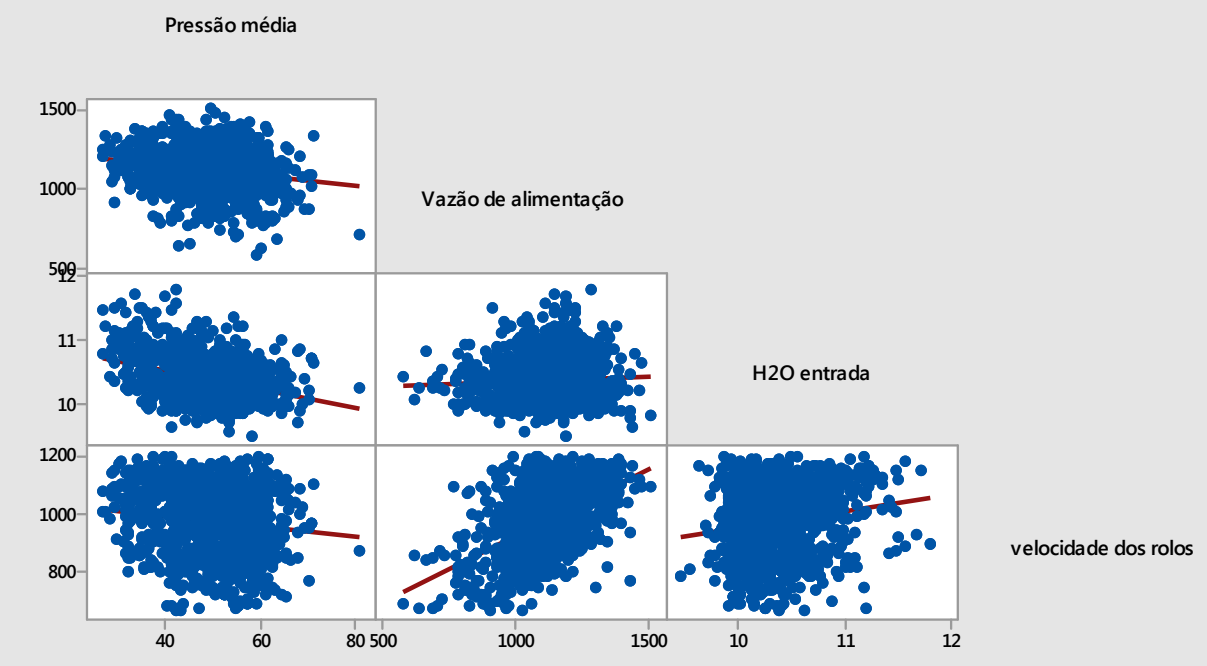

Figura 2. Interações Entre as Variáveis.

Também é importante considerar o gap de trabalho, que é a abertura existente entre os rolos durante a operação, existem três condições de gap de trabalho possíveis e que influenciam diretamente na qualidade do pellet feed prensado, são elas:

Condição de gap flutuante: Ocorre quando o gap de trabalho é sempre maior que o gap zero e ocorrem oscilações significativas durante a operação [2].

Condição de gap micro flutuante: modo em que a abertura do gap de trabalho é muito próxima aos espaçadores e devido a isto temos constantes contatos entre as estruturas dos rolos fixo e móvel com ocorrência de oscilações mínimas ${ }^{[2]}$.

Condição gap fechado: quando a abertura do gap é praticamente inexistente e as estruturas trabalham sempre encostadas uma a outra [2].

O gap de trabalho é resultado direto das propriedades do material, ajuste do gap zero e pressão de trabalho sendo que seu estado ideal é o de gap flutuante, independente das características do pellet feed que está sendo processado [2].

O trabalho se propôs a desenvolver um controle de processo baseado na necessidade de se manter o gap de trabalho flutuante e um indicador medição dos resultados, uma vez que o indicador de desempenho operacional das prensas de rolos utilizado é o "Ganho de Prensa", que nada mais é que a diferença entre os valores de superfície específica obtidos na entrada e na saída do equipamento. 
O roller press alvo deste trabalho possui, uma meta de incremento de superfície específica da ordem de $300 \mathrm{~cm}^{2} / \mathrm{g}$ [1] porém só se pode garantir esse desempenho para um tipo característico de pellet feed e taxa de alimentação que não reflete mais a realidade do processo, visto que a mudança nas características do minério é natural ao longo dos anos.

Desse modo foi desenvolvido um novo indicador de desempenho que prediz o incremento de superfície esperado em função de variáveis do minério e do próprio processo por meio uma análise de regressão múltipla baseada em dados históricos, obtendo uma equação que explica cerca de $90 \%$ das variações no incremento de superfície específica.

As variáveis escolhidas para análise foram superfície específica de saída, umidade de entrada, superfície específica de entrada, pressão aplicada nos rolos, nível da calha de alimentação e gap de trabalho, que são informações de fácil obtenção e estão entre as principais do ponto de vista operacional [3].

Foi realizado o tratamento dos dados para eliminação de causas especiais e sazonalidades. Os dados foram inseridos no MINITAB $^{\circledR}$ para determinação das variáveis que tendem a fornecer a melhor resposta em uma análise de regressão em que a resposta fosse a superfície específica de saída esperada, a ferramenta utilizada foi a Best Subsets [4].

A análise do $r^{2}$ ajustado, $C p$ de Mallows com o menor número de variáveis possível (Figura 3) visando à obtenção da variável resposta "superfície de saída" revelou ser possível utilizar tanto a umidade e superfície específica de entrada quanto a superfície de entrada e a pressão aplicada aos rolos [4].

Levando em consideração que a pressão aplicada aos rolos é proporcional a umidade do pellet feed e os dados são mais trabalhosos de se obter optou-se pela primeira opção uma vez que os parâmetros estatísticos são muito semelhantes [4].

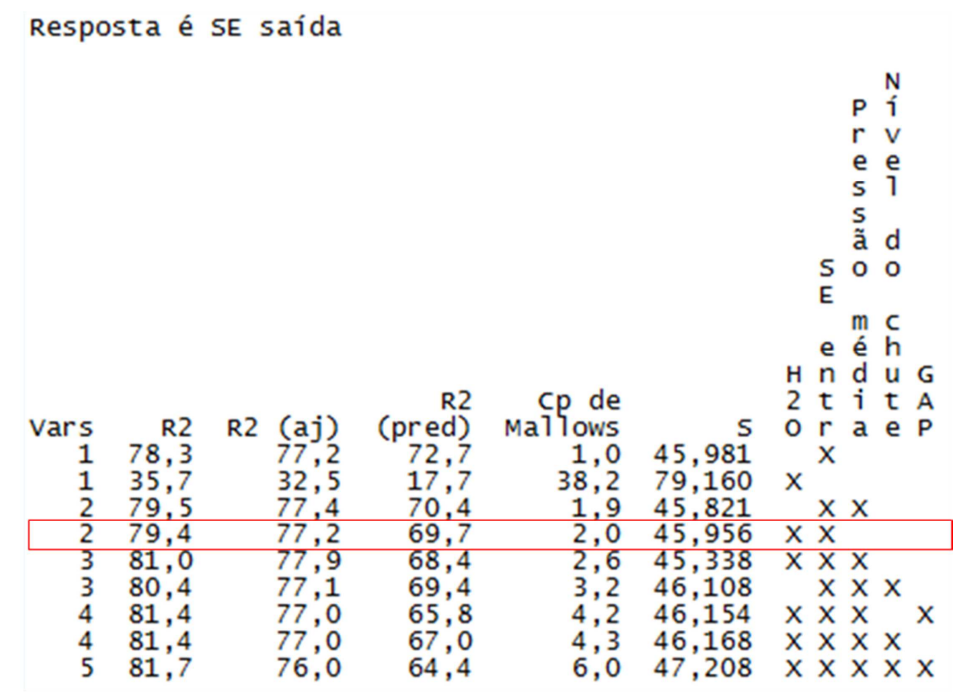

Figura 3. Análise Best Subsets.

Uma vez definido o melhor cenário procedeu-se a análise de regressão [4] para múltiplas variáveis, onde em primeira instância se obteve uma curva com $\mathrm{r}^{2}=0,81$ que se tornou a curva final com $r^{2}=0,90$ após a identificação e eliminação de causas especiais (figura 4) e (figura 5). 


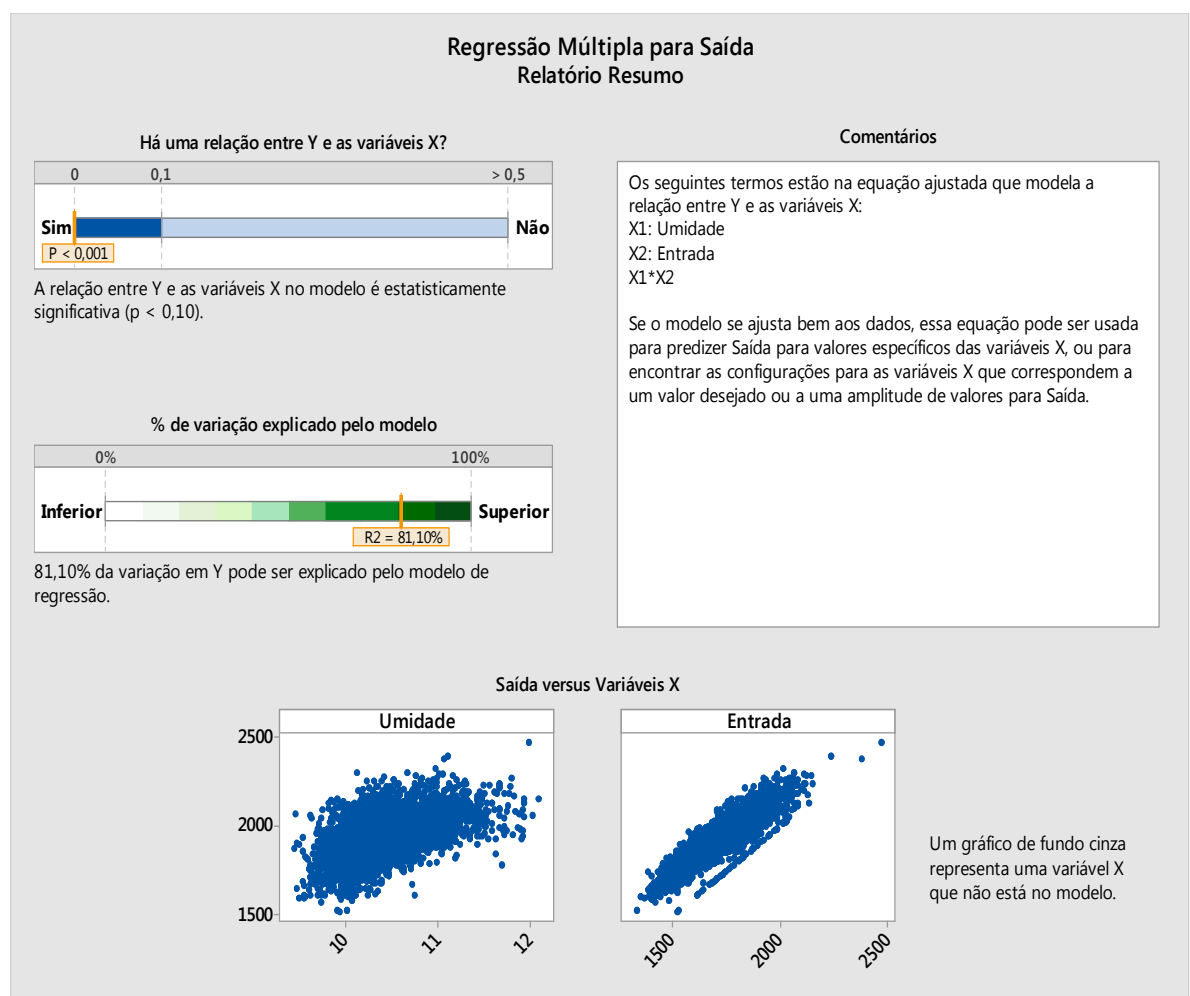

Figura 4. Primeira análise de regressão realizada.

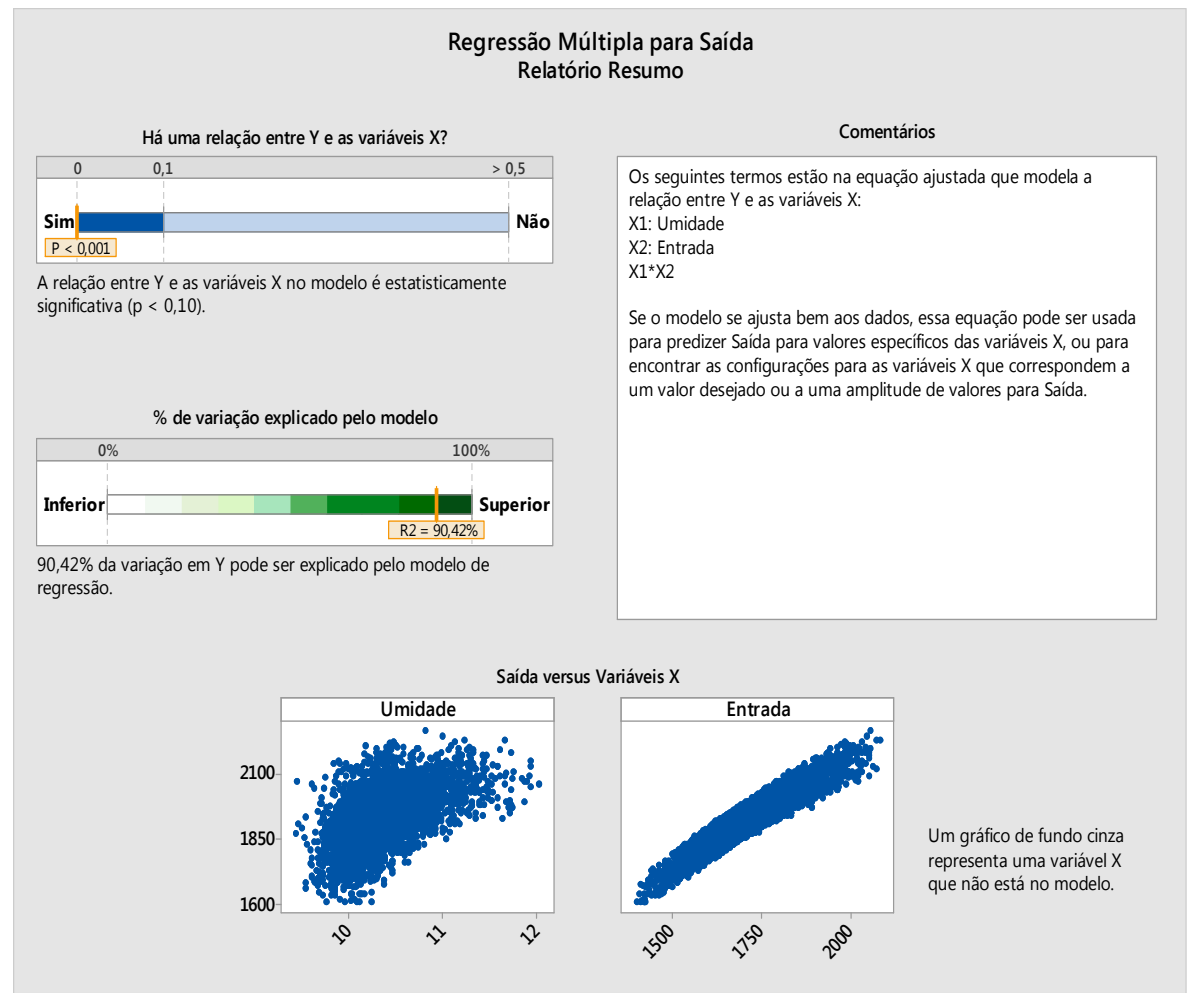

Figura 5. Análise de regressão consolidada.

A superfície específica esperada na saída do roller press (Equação 1) é utilizada no cálculo do indicador de performance de incremento de superfície específica (Equação 2). Note que $\mathrm{K}_{1}, \mathrm{~K}_{2}$ e $\mathrm{K}_{3}$ são fatores obtidos na análise de regressão.

$$
S E_{\text {esperada }}=K_{1}+K_{2} \cdot H_{2} O_{\text {entrada }}+K_{3} \cdot S E_{\text {entrada }}+K_{2} \cdot H_{2} O_{\text {entrada }} \cdot S E_{\text {entrada }}(1)
$$


Eficiência $=\frac{S E_{\text {saída real }}}{S E_{\text {saída esperada }}}(2)$

\section{RESULTADOS E DISCUSSÃO}

Após o desenvolvimento do modelo e dos estudos sobre as variáveis de maior importância no processo, foi criada uma lógica de controle baseada nas seguintes premissas:

O gap de trabalho deve se manter flutuante;

A pressão aplicada deve ser a máxima possível respeitando a primeira premissa;

A produtividade do equipamento não pode ser comprometida.

Essa lógica foi desenvolvida no sistema de automação DeltaV e funciona com um módulo para o lado acoplado do rolo móvel e outro para o lado oposto ao acoplado que determinam set points de gap de trabalho e por sua vez transferem esse pedido para os controladores de pressão adjuntos que trabalham em cascata visando maximizar a resposta do processo a variações bruscas na qualidade do pellet feed, em especial a umidade, que torna a produtividade da roller press menor.

O controle implementado monitora a velocidade dos rolos, o gap de trabalho e o nível da calha de alimentação, tornando o sistema sensível a umidade do pellet feed de modo que são possíveis dois cenários.

Em um cenário de variação positiva na umidade a calha de alimentação tenderá a subir e a velocidade dos rolos aumentar até um limite crítico onde o controle deverá incrementar o set point de gap de trabalho reduzindo assim a pressão aplicada podendo voltar a aumenta-la no processo de estabilização do nível da calha de alimentação, que é normalmente controlado em $50 \%$ do total.

Em um cenário de variação negativa na umidade a calha de alimentação tenderá a cair e a velocidade dos rolos se reduzirá para estabilizar a calha, nesse momento o controle deverá decrementar o set point de gap de trabalho, aumentando a pressão aplicada até o momento em que o processo se estabilize de modo que a velocidade dos rolos não ultrapasse 1100 RPM.

Dessa maneira o sistema garante que sempre será aplicada a maior pressão possível respeitando as premissas do trabalho aumentando assim a força específica de moagem, que é função do gap de trabalho e da pressão (Figura 6) ${ }^{[2]^{3}}$.

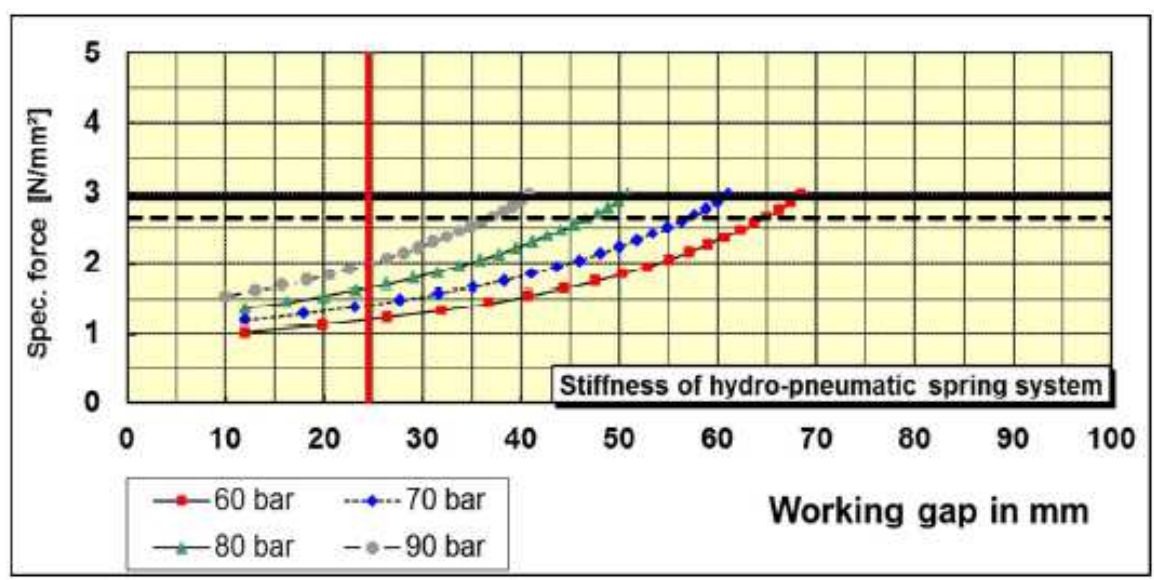

Figura 6. Força específica de moagem.

O ideal para o minério de ferro é que a força específica de moagem seja de no mínimo $1 \mathrm{~N} / \mathrm{mm}^{2}$ [2], porém como o gap de trabalho é fortemente dependente da umidade do pellet feed há casos em que não é possível atingir este valor e, além 
disso, o gap de trabalho dificilmente superará $25 \mathrm{~mm}$ mesmo a pressões de 60 bar, considerado um valor mediano, em função da umidade do pellet feed.

Após a implementação do controle foi realizado um teste on/off para determinação de sua eficácia, os resultados estão evidenciados em forma de carta de controle (Figura 7).

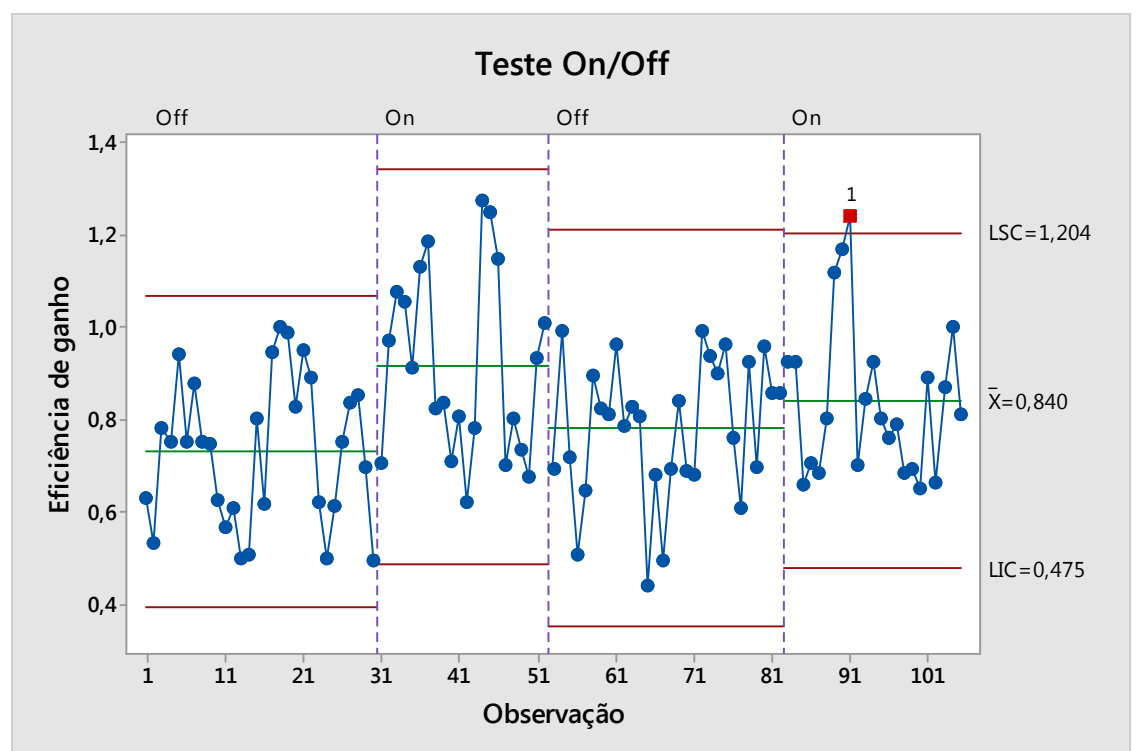

Figura 7. Teste On/Off.

Notamos que a pressão de trabalho para cada faixa de umidade sofreu decréscimo e que o gap de trabalho passou a se comportar de forma a manter-se no estado flutuante enquanto que no período anterior ao trabalho o gap tendia a se manter fechado mesmo com pressões de trabalho mais altas, o que se revelou não necessariamente vantajoso (Figura 8) [4].

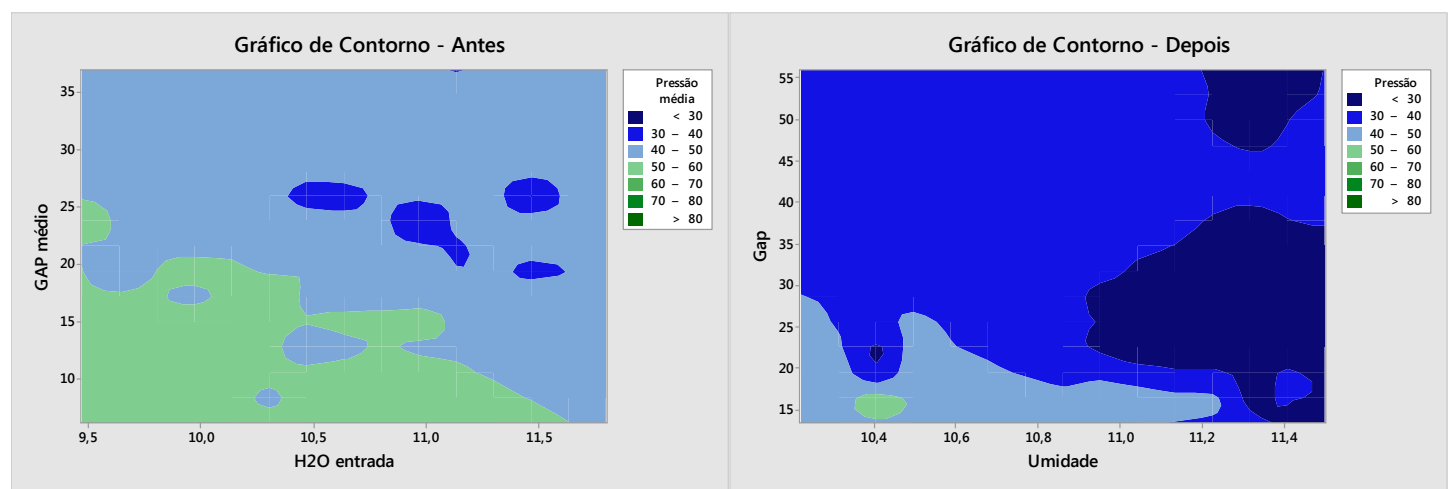

Figura 8. Comparação do processo antes e depois da implementação.

O indicador de performance de incremento da superfície específica respondeu de maneira muito positiva, aumentando de $72 \%$ para $85 \% \%$ (Figura 9 ), um salto de $18 \%$ em relação a condição anterior e além de uma redução de $16 \%$ no desvio padrão do processo. 


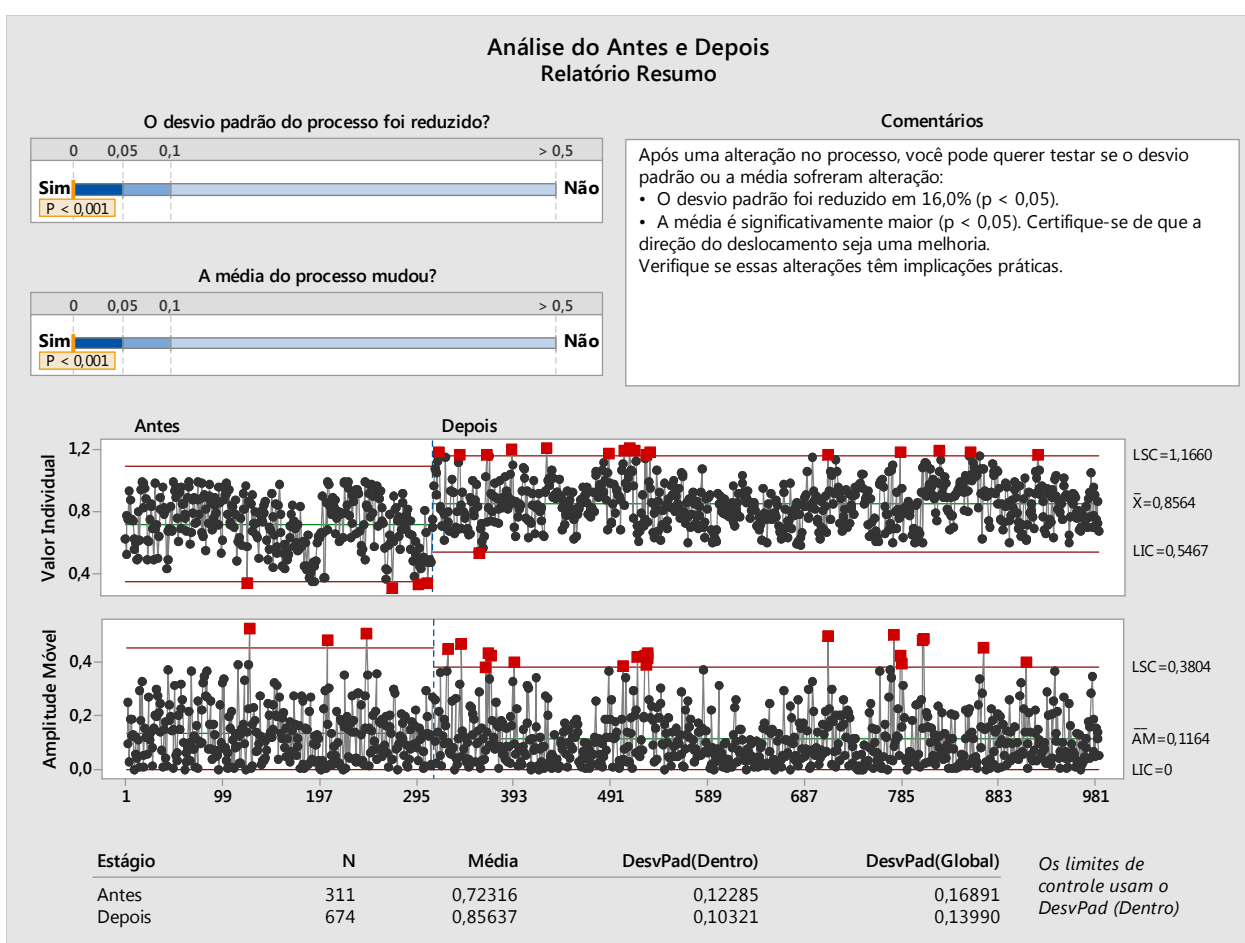

Figura 9. Resultados alcançados com o controle em operação.

\section{CONCLUSÃO}

Considerando a revisão bibliográfica levantada bem como os resultados obtidos com o trabalho de desenvolvimento do controle por gap na roller press da usina 3 na Samarco Mineração é evidente que o processo de prensagem respondeu de maneira muito positiva em relação ao indicador de eficiência da superfície de saída real em função da superfície de saída esperada, o que se traduz em melhoria no material recebido pelo processo de pelotamento bem como a qualidade do produto final entregue pela Samarco Mineração S.A.

\section{Agradecimentos}

Agradeço a toda equipe envolvida nos trabalhos de otimização dos roller press da Samarco Mineração S.A., em especial aos colaboradores do departamento de engenharia de processo e do departamento de automação além da equipe do departamento de manutenção das usinas 3 e 4 da Samarco Mineração em Ponta Ubu.

\section{REFERÊNCIAS}

1 Samarco Mineração SA. Manual Integrado da Gerência de Produção de Ubu. 2013. Revisão 01:34-38

2 Galarza, Diego. Reporte Técnico Polycom 22/17 da Samarco Mineração S.A. Anchieta, ES - 2014.

3 Silva Cavalcante, Marcos Vinícius. Artigo técnico da Samarco Mineração S.A., Otimização Das Prensas De Rolos $\mathrm{Na}$ Linha De Beneficiamento De Pellet-Feed: Controle De Torque Para Estabilidade Da Qualidade E Redução De Custos Operacionais, do $13^{\circ}$ Seminário de Automação de Processos, São Paulo, SP - 2009

4 Combat. R. Análises Multivariadas e Regressão. São Paulo: NT Desenvolvimento Gerencial; 2014. 